\title{
Port Integration in China: Temporal Pathways, Spatial Patterns and Dynamics
}

\author{
WANG Chengjin ${ }^{1}$, César DUCRUET ${ }^{2}$, WANG Wei ${ }^{1,3}$ \\ (1. Key Laboratory of Regional Sustainable Development Modeling, Institute of Geographical Sciences and Natural Resources Re- \\ search, Chinese Academy of Sciences, Beijing 100101, China; 2. French National Centre for Scientific Research (CNRS), UMR 8504 \\ Géographie-cités, Paris F-75006, France; 3. University of Chinese Academy of Sciences, Beijing 100049, China)
}

\begin{abstract}
Over the past two decades, numerous ports located in China have participated in port integration strategies, thus influencing the entire port system. The current research is initiated in order to examine the nature of port integration in China, including associated temporal pathways, spatial patterns and dynamics. Results indicate that port integration in China has been characterized by a significant increase at the turn of the 21 st century, comprising thirteen distinguishable pathways typified by differing dynamics, particularly between the northern and southern ports. Pathways were found to include 44 seaports and river ports, chiefly concentrated in the Bohai Rim, Yangtze (Changjiang) River Delta, Beibu Gulf and the southeastern Fujian, thus representing significant spatial regions. Categorically larger seaports have become the primary beneficiaries of port integration. Integration cases were divided into four categories based upon quantified dynamic magnitude including the government-driven mode, market-driven mode, government/market-driven mode and strategic alliance, and into five further categories based upon spatial extent including port internal integration, jurisdictional port integration, port integration across neighbor region, regional port integration and hub-feeder port integration. Results suggest that several factors have effectively driven port integration in China, including legislative tools and spatial planning, optimization of shoreline resources and port functionality, and port competition with the same hinterland.
\end{abstract}

Keywords: port integration; integration mode; integration pathway; integration dynamics; China

Citation: Wang Chengjin, Ducruet César, Wang Wei, 2015. Port integration in China: temporal pathways, spatial patterns and dynamics. Chinese Geographical Science, 25(5): 612-628. doi: 10.1007/s11769-015-0752-3

\section{Introduction}

Port development has been influenced by myriad drivers over the past half century, thus resulting in significant dynamic modifications within the market environment (Rodrigue, 2003). Of these aforementioned drivers, port integration strategies represent one of the primary catalysts of change. Typically, 'port integration strategies' refer to an assemblage of potential approaches for utilization by port authorities to increase operational production capacity and resources port in relation to han- dling and shipping activities, and optimize allocation of coastlines, berths, infrastructures, water and land area, shipping routes within the port system. Port integration was developed during the 1920s in the United States and other economically developed countries; however, the past decade has seen port integration become a significant global topic in terms of both public and private shareholders (Ducruet and van der Horst, 2009). This has been particularly evidenced via industrial reorganization through mergers and acquisitions within the world's terminal industry; accordingly, ports have been

Received date: 2014-03-21; accepted date: 2014-07-11

Foundation item: Under the auspices of National Natural Science Foundation of China (No. 41171108), Key Program of Chinese Academy of Sciences (No. KZZD-EW-06-02), Exploratory Forefront Project for the Strategic Science Plan in IGSNRR, CAS (No. 2012QY004)

Corresponding author: WANG Chengjin. E-mail: cjwang@igsnrr.ac.cn

(C) Science Press, Northeast Institute of Geography and Agroecology, CAS and Springer-Verlag Berlin Heidelberg 2015 
influenced by increased competitive pressures (Rodrigue, 2003), with the industry seen to undergo a process of horizontal and vertical integration (Notteboom, 2002; Slack and Fr'emont, 2005). With the global economic shift towards newly industrialized Asian regions since the 1980s, in concurrence with the Chinese 'Open Door Policy', China has experienced rapid and significant increases in GDP and trade, thus providing Chinese ports with unprecedented business (Song, 2002). Consequently, substantial port expansion schemes have been proposed in all coastal provinces. In order to circumvent potentially adverse competition between adjacent ports (i.e., disorderly or wasteful planning and construction), the coastal provinces turned their attentions to port integration strategies. The 'Opinions on Further Promoting the Development of Seaports' issued by the Ministry of Transport (MOT) in 2003 recommends port integration strategies as an effective process for the optimization of coastline resources. Hence, a notable increase in the employment of port integration has been observed in China over the past decade, leading to significant structural, fiscal and organizational change within the industry. The aforementioned changes have provided the primary impetus for the current research.

A wide range of research pertaining to the integration of transport resources is available in the published literature, however, to date, a paucity of data relating to port integration strategies exists. Stubbs and Jegede (1998), and Givoni and Banister (2006) have previously examined the integration of road, rail and aviation networks. Notably, international cargo is predominantly transported by sea; thus, major seaports play a central role in the logistical chain (Song, 2002; Song and Panayides, 2008). Typically, inter-port networking strategies comprise terminal locations, inland ports, overseas ports and neighboring ports (Notteboom and Winkelmans, 2001); thus, an appropriately operational logistics chain requires high-level port integration (Junior et al., 2003). Both Notteboom and Rodrigue (2008) and Song and Panayides (2008) have focused previous work on the assessment and influence of port integration strategies in the logistics chain. As previously reported (Notteboom, 2002; Hoshino, 2010), numerous port and terminal operators have actively sought cooperative measures for mutual benefit including both vertical and horizontal integration strategies. Additionally, a limited amount of literature has dealt with relationships among the ports, Heaver (1995) has examined the existence and nature of cooperative measures between neighboring ports, while Song (2002) suggests that obtaining and maintaining the correct balance between competition and cooperation is crucial for the future success of port operators.

The majority of previous investigations relating to port integration have been initiated to address other factors, thus resulting in a scarcity of directly focused research, particularly with respect to temporal pathways and the dynamics of port integration. Furthermore, within the published literature, there exists a failure to effectively capture the highly specific and idiosyncratic nature of national and regional reform, let alone individual ports, particularly with respect to strategy effects and outcomes (Wang et al., 2004). The rapid development of ports in China has attracted the attention of a host of specialists for the purposes of tracking and interpretation (Han et al., 2002). Slack and Wang (2002) have examined the effects of local and regional competition and cooperation faced by major Chinese ports from their peripheral ports. Significant investigative efforts have focused on the relationship between Hong Kong and other ports in the Pearl (Zhujiang) River Delta (PRD) region, particularly the Shenzhen Port (Comtois and Slack, 2000; Wang and Slack, 2000; Cullinane et al., 2005). For example, the integration between Hong Kong and Shenzhen ports, in addition to numerous other ports within the PRD has been detailed within several studies (Wang, 1998; Wang and Slack, 2000; Song, 2002; Wang and Michael, 2010). Similarly, the Yangtze River Delta (YRD) has received considerable attention over the past decade (Cao et al., 2001), as have the ongoing competition and cooperative relationships between Shanghai and Ningbo ports (Cullinane et al., 2005; Wang et al., 2007; Wang, 2008; Li and Oh, 2010). Research indicates a significant potential for growth pertaining to Yangtze River (YR) shipping; Veenstra and Notteboom (2011) theorize the regionalization phase of the YR is primarily related to Shanghai port, and Wang and Ducruet et al. (2012) analyzed the integration between Shanghai port and Yangshan port. However, ports in other regions have yet to receive similar academic attention, most notably the Bohai Rim (Lee and Rodrigue, 2006; Chen et al., 2005). Due to the identified paucity of literature focusing on port integration strategies, particularly in the context of port merg- 
ers and investments, the current paper focuses exclusively on the nature of port integration in China, with a specific emphasis on integration character, mode and regularity by drawing the timeline and temporal path, thus highlighting the specific dynamic mechanisms involved.

\section{Spatio-temporal Pathways of Port Inte- gration in China}

Port industry management systems in China have undergone continual reform since the 1990s, with similar adjustments taking place with regard to inter-port relations, thus resulting in profound changes with respect to both spatial patterns and functional structures of port systems. As might be expected, not all Chinese regions have exhibited similar timelines apropos port integration. Accordingly, all collated port integration cases over the past decade were chronologically sorted, resulting in the timetable presented in Fig. 1. Further detail and characteristics were obtained via examination of this 'integrating roadmap', as summarized in the following points:

(1) China initiated port integration strategies, with the majority of cases occurring after the turn of the $21 \mathrm{st}$ century, although it is possible to date the earliest case back to the late 1980s. In 1987 the former Huangpu and Guangzhou ports were merged, forming the current Guangzhou Port. In 1997 the MOT advocated the integration of Shanghai, Jiangsu and Zhejiang ports, resulting in the development of the Shanghai Port Group. After the 21 st century port integration was seen to enter into a particularly active phase; cases of port mergers and capital cooperation continued, in concurrence with the emergence of significant strategic alliance within the industry. As shown in Fig. 1, the 'turning point' for port integration in China may be explicitly demarcated as occurring in the year 2003, during which the MOT recommended the 'coastal ports to speed up the integration of resources, beyond administrative divisions, give full play to advantages of the port group', thus aiming to accelerate the development of China's port industry. Approximately 40 cases of port integration were seen to occur after 2003, with notable peaks during the period 2005-2006 $(n=16)$, with numbers decreasing gradually thereafter. Consequently, the continuous emergence of port integration has prompted significant restructuring within the port industry and port systems over the past decade. Interestingly, during this period of significant port integration, a general reduction in the number of operating ports was observed, in parallel with a reduction in the number of port authorities, however, abandonment of the original port area did not occur, with original ports developed into one harbor of the integrator upon integration.

(2) Port integration in China has been characterized by expansive geographical coverage, involving numerous ports, which differs from the integrating processes in developed countries, which are typified by the inclusion of lower port numbers. During the review period, 40 cases of port integration occurred on China, comprising all coastal provinces, and involving 44 categorically large or medium-sized ports (3/4 of China's large ports). Thus, China's port system has undergone significant reorganization during the review period. As previously outlined, from a geographical perspective, affected ports have been primarily located in coastal regions, with a limited number of integrating ports located along the Yangtze River, therefore indicating the different influence of international trade and domestic trade on the geographical coverage of port integration in China. More specifically, over the last two decades, export-oriented economic development has been a significant driver in the promotion of seaport expansion, resulting in an urgent demand for integration of the coastal ports. Moreover, institutional variance and the 'degree of openness' pertaining to terminal markets across regions, has also driven port integration; this has resulted in a significant geographical concentration of port integration in a specific region, including the Bohai Rim, the YRD, Beibu Gulf and the southeastern Fujian. Conversely, no cases of port integration have been associated with the PRD, a region characterized by a highly developed shipping industry, numerous port authorities.

(3) An important perspective from which to examine port integration is that of the dynamics involved. Typically, most cases develop within one of two macrocontexts, namely, port mergers or capital reorganization. These have dominated the port integration process in China, resulting in similar importance and normally following an equivalently parallel process. Port integration in China has exhibited a distinctly spatial disparity between northern and southern ports, typified by the employment of significantly different integration me- 
chanisms. Northern ports have focused on integration by means of capital and stock shares, thus emphasizing the 'market-based' mechanism, with terminal operators often playing a dominant role during the process. Conversely, southern ports have more often than not applied administrative forces to merge the ports, with the local and national government playing a dominant role (Notteboom, 2002; Pallis et al., 2008). The process of two or more ports being managed by a single port authority is commonplace within many regions outside China (Hoshino, 2010). There has been a marked spatial differentiation in terms of observed economic patterns insofar as planned economies were and are mainly developed in the northern China while the market economy in the southern China showed elevated development i.e., an apparently negative correlation is observed between governmental intervention and market mechanisms. Further, port integration has exhibited differential characteristics and modes during each period; prior to 2004, the majority of ports applied either direct mergers or capital reorganization to achieve effective integration, with jointly functioning administrative and market mechanisms. However, after 2004, capital penetration or investment (such as the joint ventures and stakes) has become the primary integration mode, with market mechanism playing a more dominant role (Junior et al., 2003). Accordingly, governments have typically played a dominant role in order to cultivate and manage port integration processes, particularly during initial stages. Subsequently, governmental dominance has given way to enterprise (i.e., terminal operators) or market forces within a more matured and experienced environment.

(4) To date, port integration in China has developed into 13 evolving pathways (Fig. 1), thus presenting a significantly regionalized feature potentially determined by physical condition, regional economics and regional administration. Moreover, pathways seem to be dominated primarily by integration mode, with progression taking place independently, as evidenced by the lack of operational overlap prior to 2006 . The large and medium-size ports form the nucleus of each pathway matrix, with the mega ports in particular playing the role of advocators and executors of port integration strategies, in addition to being the primary beneficiaries via strengthening their position within the overall port system e.g., Dalian, Yingkou, Qinhuangdao, Tianjin, Yantai, Qingdao, Rizhao, Shanghai, Suzhou, Ningbo,
Fuzhou, Xiamen and Beibu Gulf ports. These ports may also be approximately divided into two levels in terms of throughput volume; the first level represents the large hub ports including the abovementioned mega ports, the second cluster primarily are comprised of small and medium-sized regional ports with significant influence over regional integration.

(5) Modes of port integration are observed as being significantly diverse in terms of the level of formality applied, varying from informal programs of cooperation to advanced strategic alliances, joint-ventures or mergers and acquisitions (Notteboom and Winkelmans, 2001; Junior et al., 2003); thus reflecting the differing dynamics involved, particularly market and governmental mechanisms. Overall, 12 cases of port mergence and 28 cases of capital reorganization were encountered during the review period, while strategic alliance and government/market-driven integrations were represented by five and two cases, respectively. Notably, each mode was seen to generate variable 'integrational adjacency' among players; for example, port mergence is characterized by the highest level of 'integrational adjacency', thus effectively achieving the unification of port planning, construction, management and terminal operation. Conversely, strategic alliance has been characterized by administrative and operational independence (Lam and Yap, 2011; Veenstra and Notteboom, 2011), such as a 'port alliance along the Yangtze River' in Jiangsu and multilateral cooperation with Hamburg and Bremerhaven ports and the European Sea Ports Organization (ESPO). During the early periods of port integration in China, the integrative process was dominated by government-driven modes, particularly port mergers, in concurrence with weak market mechanisms. In recent years, administrative forces have gradually weakened with market forces playing an increasingly dominant role, as particularly evidenced by the increasingly significant role of terminal operators.

(6) Port integration is multi-leveled in nature, comprising integration between large ports and small/medium-sized ports (with the former merging with the latter), between small and medium-sized ports (with the weaker typically merging with the stronger e.g., Zhangjiagang and Yangzhou ports) and between the large ports; however, the integration of small/medium size ports with larger ports is the most commonplace in China. Larger ports apply not only the capital ap- 
capital approaches to integrate the large port but also the merger to integrate smaller ports. Consequently, port scale and strength typically determine the mode of port integration. Integrations between larger ports were frequently undertaken with the support of central government, while integration between large ports and small/ medium- sized ports have been implemented under the auspices of provincial or prefectural-level government.
For example, port integration in Liaoning Province was actively promoted by the relevant provincial government, whereas, the integration of Yantai and Longkou ports was undertaken with support from Yantai $\mathrm{Mu}-$ nicipal Government. Partial impetus tends to stem from the delegation of controlling powers being transferred from central to local governmental departments. Additionally, port integration was not formally developed as

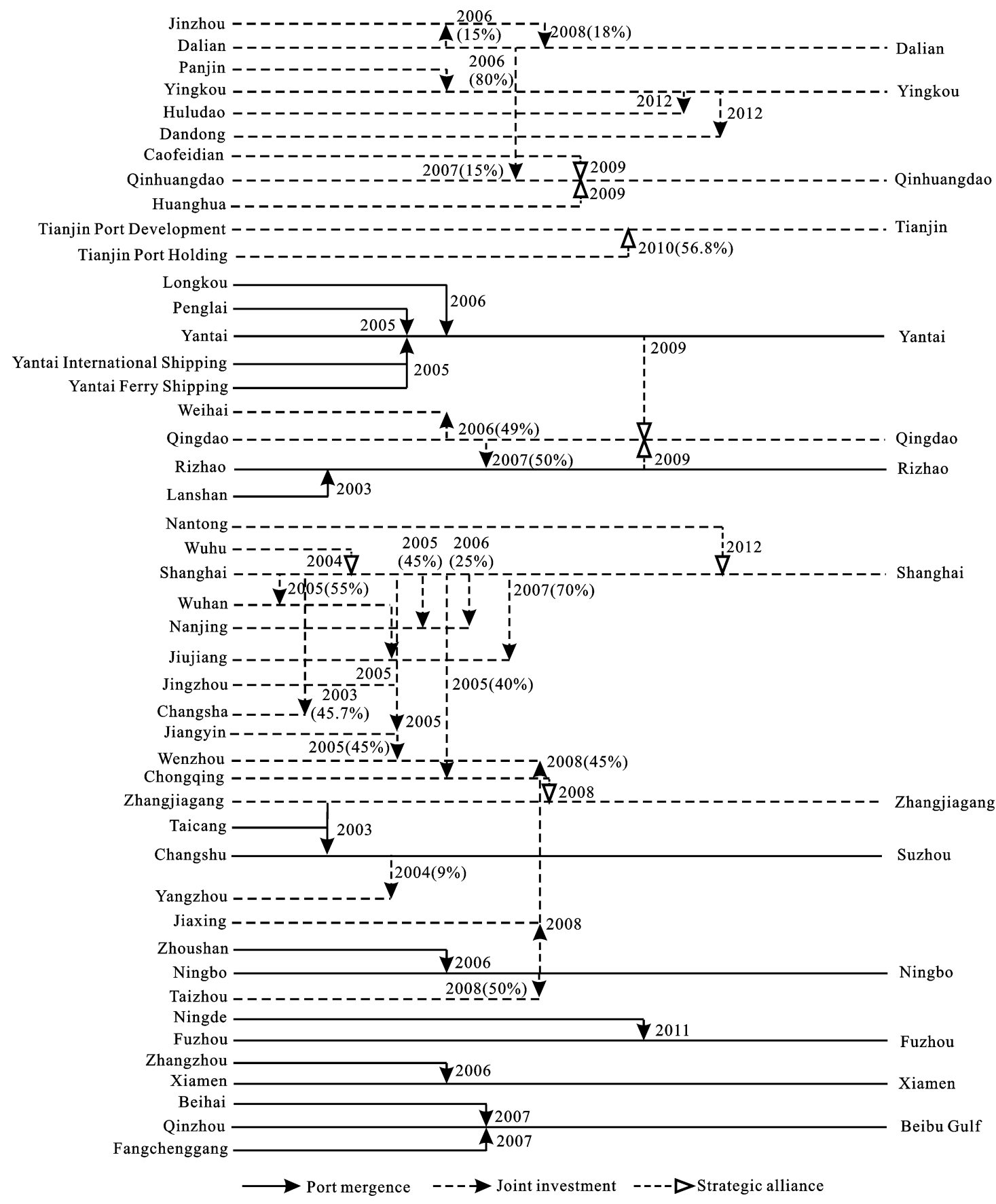

Fig. 1 Temporal pathways and port integration modes in China. 2007 is the year in which the port integration happened; (50\%) is the sharesholding which the integrator holds; arrow refers the integration path pointing at the integrator 
a complex or multilayered structure, instead being primarily divided into two distinct layers, characterized by core ports ('initiative partner') and secondary ports ('passive partner'). Of late, a three-layered structure has emerged among several ports, including Lanshan, Rizhao and Qingdao, with this structure beginning to gain impetus. The emergence of this three-tiered structure has resulted in the interweaving and overlapping of port integration pathways; efforts are currently underway to simplify and decrease these pathways over a period of time.

\section{Modes of Port Integration in China}

\subsection{Studying region and data}

The studying region includes the provinces with the port, including seaport and river port, and excludes Hong Kong, Taiwan and Macao because of the difficulties for obtaining the data. More specifically, this region involves Liaoning, Tianjin, Hebei, Shandong, Jiangsu, Shanghai, Anhui, Zhejiang, Fujian, Guangdong, Guangxi, Hainan, Chongqing, Hubei, Hunan and Jiangxi provinces. The collection of data was critical to the successful completion of the current paper; obtaining relevant systematic statistical data proved problematic. The majority of data pertaining to both specific cases and shareholding were primarily derived from the website of each port, terminal operator and/or port authority. Data relating to port throughput were obtained from The Year Book of Chinese Transportation (2013) (China Transportation \& Communications Press, 2014). Data for coastlines length and water-depth were collated from the local governmental planning department for each port including the Dalian, Yingkou, Qinhuangdao, Tianjin, Yantai, Qingdao, Rizhao, Shanghai, Suzhou, Ningbo, Fuzhou and Xiamen ports.

Due to the inherently different backgrounds pertaining to port integration within specific regions, analysis of port integration is necessarily undertaken within two different contexts, namely dynamic mechanisms and spatial dimensions, thus permitting mode determination and further revelation of general trends and characteristics. The matrix presented in Table 1 and Fig. 2 has made it possible to ascertain the extent of differentiation pertaining to port integration in China, thus allowing the authors to explicitly define and verify several integration modes.

\subsection{Dynamic mechanism differentiation of port integration}

Based upon differentiation of determinative forces and the market or governmental approaches with respect to port integration, cases of port integration during the review period have been categorized into four types: government-driven, market-driven, government/market-driven modes and strategic alliance (Table 1). While administrative and market forces have been shown to frequently converge they represent diverse roles within integration modes, similar to trends highlighted with respect to spatial coverage variation. To date, port integration implementation has varied from port authority mergers or acquisitions to informal strategic partnerships via strategic alliance (Notteboom and Winkelmans, 2001).

(1) Government-driven modes: as previously defined, a port is an operational and political unit (Wang et al., 2004) with the port industry generally characterized by substantial governmental involvement (Pallis et al., 2008). Traditionally, governments take primary initiative for port development through a public port authority, thus playing a key role in port planning, investment and management, by focusing the provision of both the superstructure and infrastructure pertaining to loading/unloading, temporary storage and intra-port operations (Rodrigue, 2003; Pallis et al., 2008). Accordingly, governments are considered a significant driving force with respect to port integration strategies, with the importance of the public sector having been reflected by the case of the New York/New Jersey port (Rodrigue, 2003). Government-initiated mergers or take-overs have been a major tool within the global terminal industry, with this trend now particularly evident in China (Junior et al., 2003). Government-driven integration is typically undertaken via the creation of regional or national development strategies, whereby, the government in question merges two or more ports, thus establishing a new port authority for the implementation of unified port planning, construction, operation and management. Consequently, the operational catchment area is increased, resulting in theoretically increased throughput and productivity, thus strengthening the overall market share of the newly integrated port (Hoshino, 2010). Within the review period, $25 \%$ of cases $(n=10)$ have been characterized with this mode, including Suzhou, Rizhao, Yantai, Ningbo-Zhoushan, Xiamen, Beibu Gulf and Fuzhou. All these cases were undertaken under the 
direct influence and auspices of their respective provincial government. In many coastal provinces, governments have advanced port integration as the official provincial strategy via the promulgation of guidance, establishment of institutions and development of preferential policies for directing and encouraging port integration. Government-driven integration have been reported as generating close integration and development of rational divisions among ports with the overall objective of creating a 'joint force', and in some cases, the construction of inland collection and distribution networks. While this mode typically avoids disorderly competition, it will not result in an overarching elimination of competitive forces, due to investments made by various terminal operators frequently resulting in intra-port or inter-terminal competition. This mode may be particularly significant in terms of port integration when unilaterally initiated across administrations. For example, in 2004, a jointly developed proposal comprising six port authorities ('High attention to reform of port management system in Fujian Province') was submitted to the Fujian provincial government; in 2007, the Fujian government issued a guidance document 'Overall Planning of the United Reform of Port Management in Fujian Province', proposing that all ports in Fujian be integrated into Xiamen, Meizhouwan and Fuzhou ports. In the case of such integrative processes, the relevant united port authority becomes a prerequisite for port mergers and an active tool for the exertion of administrative mechanisms, e.g., Suzhou Port Management Commission (2003), Ningbo-Zhoushan Port Management Committee (2006). Accordingly, as frequently observed, two or more ports are often managed by a single port authority, such as Los Angeles-Long Beach port, and Tokyo Bay port. In particular, the Port Authority of New York/New Jersey was established by two state authorities in 1921 for the management of seaports, airports, bridges, tunnels and bus terminals within the delineated operational area. This was and is a particularly unique example, in that it incorporates two economically and politically powerful states (Rodrigue, 2003; Hoshino, 2010). Conversely, this mode represents inherent difficulties, particularly in terms of port integration over a wider geographical range and potential deviation from market demands.

(2) Market-driven modes: the market environments in which ports have traditionally operated have undergone dramatic changes; thus resulting in the development of a new integration mode. An outcome of the market mechanism has been the capital penetration mode, defined by development of joint terminal ventures for port integration via application of joint investments, acquisition purchases or the stock exchange (Junior et al., 2003). This mode is characterized by an aggressive growth strategy based on acquisition of existing terminal assets or construction of new terminals via the sharing of both capital benefits and investment risks. Unsurprisingly, joint terminal ventures are now commonplace with partners typically comprising the relevant port authorities and/or state-owned terminal operators (Junior et al., 2003). This mode is also characterized by decreased governmental association and its concurrency with the market mechanism as implemented by the enterprise. Despite integrated ports having a traditionally close relationship with market demands, they may also suffer from less formalized levels of integration, thus producing partial joint forces due to the potential inherent disconnect with regional or national concerns. As previously propounded by Notteboom and Winkelmanns (2001), this mode also reflects the port networking strategies of terminal operators i.e., formalized coordination. Numerous previous cases of port integration are categorized within this mode, representing $45 \%$ of China's integration cases during the review period. Since 2003, Zhangjiagang/Yangzhou, Shanghai/Wenzhou (Jiangyin, Wuhan and Jingzhou), Yingkou/Jinzhou, Qingdao/Weihai, Qingdao/Rizhao, Dalian/Qinhuangdao, and Ningbo/Taizhou (Jiaxing, Wenzhou) have successfully employed joint terminal ventures for port integration. Shanghai Port previously developed and implemented the 'Yangtze River Strategy' in order to invest the construction of Wuhu, Nanjing, Jiujiang and Chongqing ports. Specifically, operators have opted for the utilization of joint ventures with local partners (i.e., port authority, operators or other types of enterprises) in order to attain and maintain successful operations within the confines of local commercial, economic and governmental environments (Notteboom and Rodrigue, 2012). Circumstantially, the development of stakeholder communities may be significantly complicated in comparison with traditional state monopolies (Notteboom, 2002). This is particularly the case as mutual shareholding activities are significantly more frequent in China's current political and economic environment. 
The inherent limitation associated with this integration mode is the partial integration of port resources, potentially resulting in convergent functionality among ports in question. Moreover, competition may be extended from being inter-port in nature to intra-port or even inter-terminal, thus resulting in potentially repetitive construction; operators more frequently benefit from horizontal port integration (Notteboom, 2002). This mode may be more suited to port integration with an inherently wider geographical coverage, such as the cooperation between Rotterdam Port in Holland and Antwerp Port in Belgium.

(3) Government/market-driven modes: this mode typically applies to capital investment or mutual shareholding in the presence of governmental support, for the integration of ports across administrative areas, with only slight changes to the existing patterns of port administrative structure, e.g., Shanghai-Yanshan port. Yangshan port is located within the administrative area of Zhejiang Province, however its development and construction has been overseen by Shanghai, with Shanghai Port Authority currently responsible for port management. Various other relevant examples include the integration of Yantai Port, Yantai International Shipping and Yantai Ferry Co. in 2005, the establishment of joint terminal ventures by Dalian and Jinzhou ports within the remit of Liaoning Government in 2006 and the stockholding acquisition of Tianjin Port Holding by Tianjin Port Group with the support of Tianjin Government in 2010. Zhejiang Province has previously proposed that Ningbo port construct new terminals at Jiangxing Port (Cullinane et al., 2005). This mode has also been previously applied in Europe, for example, the integration of Antwerp and Zeebrugge ports in Belgium. Most cases characterized by this mode are not based solely upon market incentives, with regional political and social networks additionally considered (Airriess, 2001).

(4) Strategic alliances: in order to counteract a shortage of port resources, ports associated with complementary resources and/or related enterprises located at various positions along the logistical chain may undertake negotiations based upon continuing independent operation. An informal strategic alliance may be entered into, thus ensuring the development of long-term cooperative relationships. The underlying operational mechanism associated with this mode is regular scheduling of alliance conferences and the formulation of organizational treaties in order to create and maintain an orderly market. This mode offers examples, with a typical case being the Shanghai Port Groups proposal via the Chinese State Council in 1997 involving Nanjing, Zhenjiang, Zhangjiagang, Nantong, Ningbo and Zhoushan ports. This was established for the effective regulation of competition and promotion of the development of container ports in Shanghai, Zhejiang and Jiangsu provinces. However, at its core was the development of a feeder network for Shanghai port from other ports especially the ports in the Yangtze River Vallye (Lam and Yap, 2011). Other pertinent examples include the 'Port Alliance along the Yangtze River' in Jiangsu in 2005, the strategic cooperation between Zhangjiagang and Chongqing ports in 2008, the cooperative agreement of Suizhong harbor between Huludao and Yingkou ports and of Haiyanghong harbor between Yingkou and Dandong ports in 2012 (Table 1). A typically cited example from Europe is the establishment of the ESPO in 1993, albeit, this comprised the development of an industrial association as opposed to a cooperative agreement. However, if port authorities do not appreciate the potential benefits of this mode, it is likely that its use will decline in future. China's current port policies are characterized by a decentralized approach for stimulation of competition, while strategic alliances have appeared to focus on the establishment of hub ports for the regions that they serve (Cullinane et al., 2005). This mode is most frequently employed between hub ports and feeder ports, thus, it encompasses a strategic approach for the hub to enlarge the hinterland or enhance its cargo supply.

\subsection{Spatial coverage differentiation of port inte- gration}

With the broader context of spatial dimension, not all integration cases in China during the review period exhibited comparative spatial modes, with differing coverage at various scales from the port interior to the region frequently observed (Fig. 2). Within the context of jurisdictional divisions including jurisdictional scope and administrative rank, integration within a port $(n=2)$ and within a prefectural-level region $(n=3)$ were found to be represented by very few cases, with the majority of cases occurring at the provincial scale $(n=18)$, thus effectively exhibiting the potentially positive and active role of provincial government in port integration processes. 


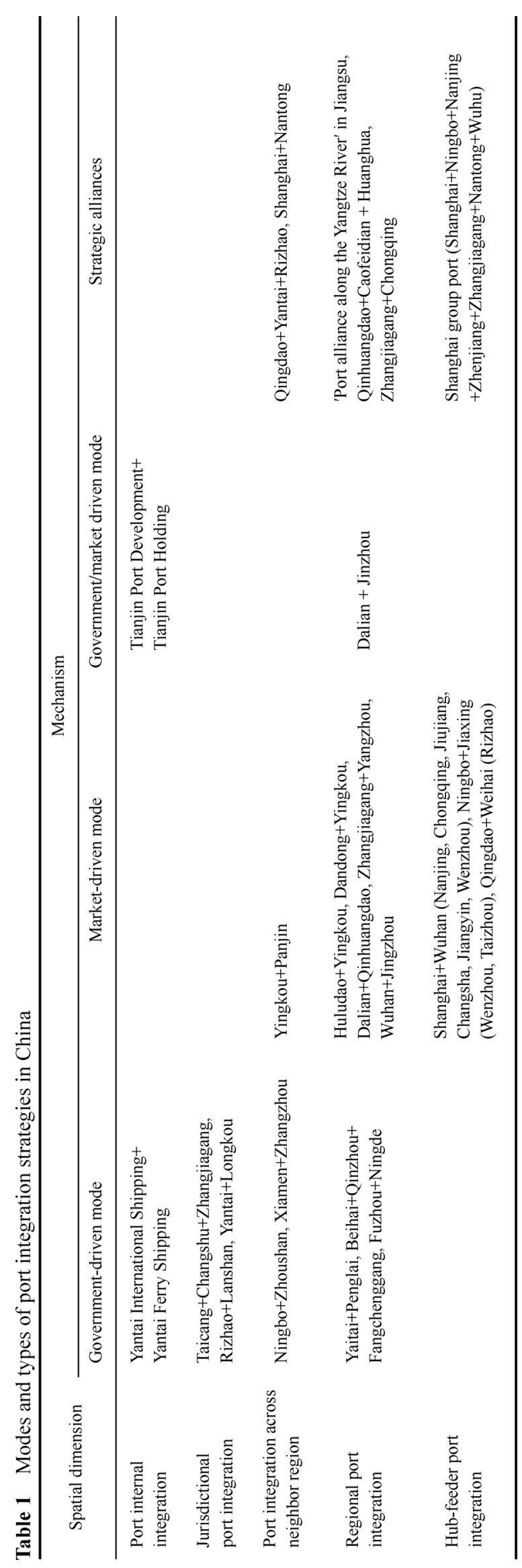


Moreover, findings reflected a slightly different trend than that typically observed in developed countries insofar as eleven cases of port integration occurred across provinces. In order to more adequately consider the importance of spatial regularities upon the port integration process, cases from the review period were classified into five categories in the Table 1, as follows:

Category I: port internal integration. Occasionally, internal port resources may belong to several terminal operators or institutions. According to the allocation regularities of transport resources, individual owners may integrate these resources characterized by the same location but diverse ownership, thus developing integration relationships between separate terminals and/or operators located within the same individual port. This category includes cases of internal integration between Yantai International Shipping and Yantai Ferry Shipping, and between Tianjin Port Development and Tianjin Port Holding. These integration efforts were primarily undertaken by the individual enterprises.

Category II: jurisdictional port integration. This category refers to instances of ports characterized by differing locations but within the same prefectural region and their establishment of a new united port authority integrated resources and one overarching port name. Typically, integration cases within this category successfully achieve unification of port planning, management, construction and operation. Subsequent to the integration process, the original ports, having relatively adjacent locations, transform into different 'sister' harbors of one new port. Notably, the majority of cases associated with this category were characterized by government-driven port mergers, including Suzhou port originating from Taicang, Changshu and Zhangjiagang ports, Rizhao port from Rizhao and Lanshan ports, and Yantai port from Yantai and Longkou ports (Fig. 2).

Category III: port integration across neighbor regions. Ports assigned to this category belong to the different prefectural regions, are located within the same bay and share the same navigation channel and hinterland. This category focuses on the integration of port resources within one jurisdictional location owned by two or more port authorities and is based upon several factors including not only regional regulatory and social networks but also the scientific and rational utilization of shoreline resources (Airriess, 2001). Typically, the regional or local government considers the influence of administrative boundaries, thus negating these potential operational burdens for the implementation of unified port planning, construction, operation and management

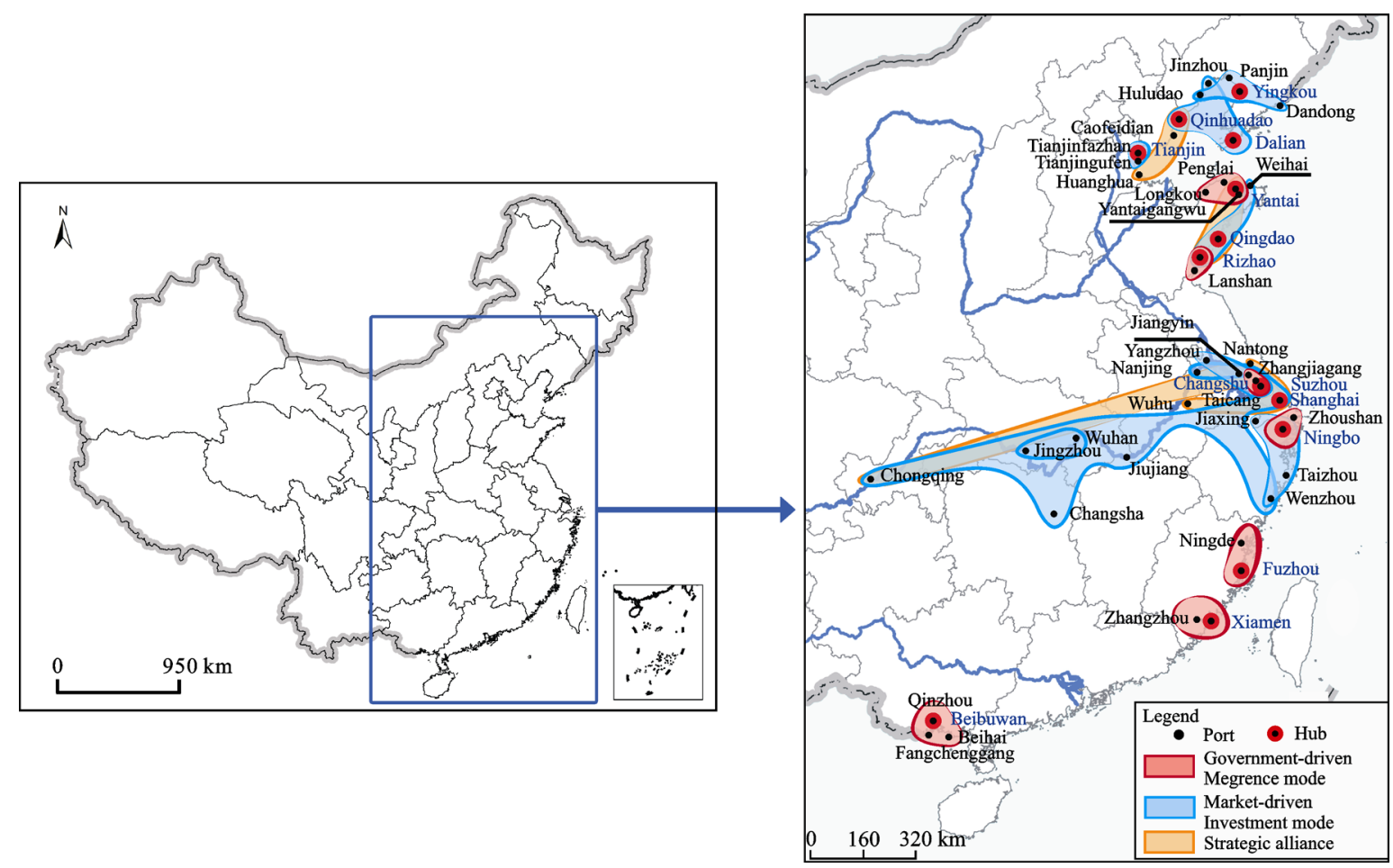

Fig. 2 Spatial pattern and modes of port integration in China 
founded on the physical attributes and economic regularities of the specific ports and coastline. Moreover, it also transforms inter-port relationships into intra-port relationships, similarly, transforming port competition into internal division and cooperation. In the majority of cases, this is implemented through a port merger and the establishment of a new port authority, although several cases also belong to the capital cooperation modes of integration. Typical cases include 'Ningbo + Zhoushan', 'Xiamen + Zhangzhou', 'Yingkou + Panjin' and 'Shanghai + Nantong'. Numerous cases within developed countries may also be categorized in this way, such as the merger of Los Angeles and Long Beach ports. In particular, the aforementioned New York/New Jersey port in addition to the Copenhagen/Malmö port are both cases in point with two port authorities managing ports outside their original jurisdictions (Hoshino, 2010).

Category IV: regional port integration. Ports located within two or more jurisdictional areas regardless of separating distance are integrated cross-regionally. A majority of cases assigned to this category are implemented via port mergers based upon governmental support or joint ventures based on capital cooperation. They are typically characterized by diverse objectives and dynamics, such as the optimization of shoreline resources or the elimination of unhealthily aggressive competition. This category comprised the following cases: 'Yantai + Penglai', 'Beihai + Qinzhou + Fancheng', 'Fuzhou + Ningde', 'Huludao + Yingkou', 'Dandong + Yingkou', 'Dalian + Qinhuangdao', 'Zhangjiagang + Yangzhou', 'Wuhan + Yangzhou', 'Dalian + Jinzhou' and 'Port Alliance along Yangtze River' in Jiangsu. Cullinane et al. (2005) have also previously assigned the 'Shanghai Port Group' to this spatial coverage category. The most prominent cases of regional port integration outside of China are the port merger of Malmö and Copenhagen in Sweden and Denmark, respectively (Hoshino, 2010).

Category V: Hub-Feeder Port Integration. In order to expand hinterland, thus ensuring future cargo supply, a hub port located at the regional gateway may actively integrate a feeder port within the same hinterland or located on an adjacent coastline. This category is categorized by inter-port cooperation in terms of the logistical chain and the development of feeder shipping networks. Shanghai port has previously proposed a strategy to develop a feeder network which aims to secure trans- shipment cargoes from other coastal ports and inland river ports, thus optimizing its deep-sea port facilities. As set out by Cullinane et al. (2005), this proposal specifically objectifies the development of a container logistics and distribution network subsequent to successful expansion along the YR; Veenstra and Notteboom (2011) noted that Shanghai port has established several joint ventures in order to profitably integrate feeder ports including Wuhan, Nanjing, Chongqing, Changsha, Jiangyin, Jiujiang, Nantong, Zhenjiang and Zhangjiagang ports, in addition to the integration of Wenzhou Port. Furthermore, the 'Three Gorges Dam' project has significantly enhanced navigability on the YR, permitting upriver transit as far as Chongqing (Cullinane et al., 2005). Through the effective development and occupation of inland terminal facilities, Shanghai Port has potentially established a successful model for the port regionalization process in China (Veenstra and Notteboom, 2011). The northern regional hub of Qingdao port has also successfully integrated numerous smaller ports in the Shandong Province including Weihai and Rizhao ports. Similarly, the trunk port of Ningbo has effectively integrated the nearby ports of Wenzhou and Taizhou as feeder ports in addition to the construction of a new terminal at Jiaxing in order to permit operational competition with Shanghai port (Cullinane et al., 2005). Ensuing cargo transshipment will allow transit managers to operate larger vessels, increase service frequency and necessitate fewer port calls. Summarily, this category is primarily associated with capital penetration, although strategic alliance is also a significantly employed approach.

\section{Dynamics of Port Integration in China}

Since the turn of the 21 st century, coastal ports in China have entered a phase of rapid expansion, with concurrently increasing operational capacities and increasing competition. Accordingly, these 'push and pull' factors have created a new dynamic environment within which port integration is taking place. These changing causative factors and their underlying mechanisms have been examined, and are presented in the following section.

\subsection{Governmental regulation and spatial planning guidance}

Traditionally, the port industry in China has fallen under 
the remit of highly centralized control, with direct intervention of the MOT via strict port regulations, associated with all port activities (Wang et al., 2004). The Port Law of 2003 essentially abolished dual leadership of ports, with the central government transferring all port management powers to local governments, resulting in numerous 'national ports' being reassigned as 'provincial ports' (Wang et al., 2004). The former port authorities were replaced with both a port administration bureau and a corporate business entity (Wang et al., 2004; Slack and Fr'emont, 2005), leading to the emergence of the aforementioned market mechanism. Accordingly, the past two decades have seen various levels of local government gaining increased control over the port sector within their jurisdictional area in the dual roles of both landlord and regulator. Moreover, this has resulted in a shift from central to local government in terms of port development regulation. Due to the relative operational monopoly attributed to ports and the resulting localization of port's economic benefits, the aforementioned shift in governmental remit in concurrence with industry deregulation means ports have been actively encouraged to represent a key fiscal resource within their operational area. Hence, local governments are keen to initiate the construction of local ports (Airriess, 2001). Numerous plans have been introduced for the expansion of handling facilities, the provision of supporting policy, infrastructural investment and land resources for port construction (Pallis et al., 2008). These have prompted ports of varying scales to initiate expansion programs, thus copper-fastening the increasingly intensified competition associated with port construction. This has led to concerns within local government with respect to disorderly port construction, resulting in the re-establishment of governmental supervision of port construction once again, albeit under the remit of local as opposed to central governmental departments. Accordingly, it is theorized that the active role taken by central and local government had a profound effect on port development in China, particularly during the early period of port integration, during which the government-driven integration mode was developed. Moreover, port deregulation has also promoted the increasing influence associated with the market mechanism, with the market-driven integration mode seen to develop and even predominate during the later phases of port integration.
Experience from developed countries would seem to indicate port planning has frequently provided both a foundation and guidance for future port integration processes. This dynamic has been even more apparent in China, where port planning has provided a legal support framework for the government mechanism. Under the auspices of the Port Law, the primary responsibility of central government currently rests solely with the strategic planning of port systems on a national scale. Provincial governments are typically expected to undertake master port planning, whereby port development structures are explicitly set out and relevant local policy and regulatory tools are formulated (Pallis et al., 2008).

Particularly at national level, top spatial planning or port system planning represents a key influence on port integration measures. In 2003, the MOT proposed 'coastal ports to speed up the integration of resources, beyond administrative divisions, give full play to advantages of the port group'. This policy resulted in the promotion of numerous port integrations across administrative boundaries and even provincial units. In 2004 the 'Construction Planning of Seaports in the Yangtze River Delta, Pearl River Delta and Bohai Rim (2004-2010)' issued by the State Council proposed to apply governmental regulation and capital linkage to initiate the integration of ports. The plan promoted rapid development via the market-driven integration mode. Subsequently, the State Council promulgated the $\mathrm{Na}$ tional Costal Port Distribution Planning in 2006 to direct port integration strategies. The aforementioned plan thus motivated a subsequent port integration boom, in concurrence with increased diversification of integration modes, as characterized by the development of the government/market-driven integration mode and strategic alliances and an increasingly expansive spatial coverage being associated with port integration across the Chinese provinces. Both regional planning and port master planning have also been observed as exhibiting particular significance with respect to the dynamics of port integration in China. The Outline for the Construction of Taiwan Strait Western Side Economic Zone issued by Fujian Province in 2004 vigorously advocated the 'unification of port resources in Xiamen Bay and Meizhou Bay'. Subsequently, Xiamen and Zhangzhou cities jointly formulated the Xiamen Port Master Planning document, alongside the integration of these two ports into a new Xiamen Port. Moreover, Liaoning 
Province duly proposed the integration of Dalian, Dandong, Yingkou, Jinzhou, Panjin and Huludao ports in Development Planning on Coastal Areas in 2009. The plans outlined above have accordingly developed into a significant legislative foundation for the governmental implementation of port integration strategies. Notably, while the regional plan emphasizes diversified port integration across administrative boundaries, the port plan attaches elevated importance to government-driven port mergers.

\subsection{Shoreline resource complementarity harm- onization and port function optimization}

In reality, shoreline resources is a significant factor underlying port integration. In concurrence with increasingly larger vessels, the strategic resource value of scarce coastline suitable for deep-water berthing continues to increase, thus placing greater emphasis on the rational use of these coastlines and their demands within the port integration paradigm. Governmental forces continue to determine primary terminal characteristics (e.g., size, location) and retain a level of control over the organizational sector of the terminal market (Rodrigue, 2003). Within this context, the government plays a critical role in the optimization of shoreline resources on adjacent coasts, particularly those located within the same natural bay or harbor. Based upon the physical attributes and locations pertaining to specific coastlines, coastal provinces frequently undertake unified planning, construction and management of shorelines as a precursor to port integration in densely clustered port areas within their jurisdictional area. This is enacted in order to encourage and enhance healthy competition via shoreline complementarity. For example, Ningbo and Zhoushan ports enjoy a strong mutual complementarity of their shared and respective coastal resources. Zhoushan port owns $183 \mathrm{~km}$ of operational coastline, the majority of which is $>10 \mathrm{~m}$ depth, although only $10 \mathrm{~km}$ of this is currently fully developed and operational. Conversely, the adjacent Ningbo Port suffers from a lack of deep-water coastline. Through merging of the two ports, Jintang Island in Zhoushan effectively operates as a deep-water subsidiary of Ningbo Port, thus compensating for its lack of operational deep-water, while Ningbo Port has effectively solved funding shortages previously associated with Zhoushan Port. Significantly, coastal regions associated with a 'one bay-multi ports' operational setup more urgently require unification for the effective development of coastline resources and consequent optimization of port functionality; geophysical shoreline attributes and administrative systems are likely determinants of the dominance of the government-driven integration mode, particularly in the case of port merger dominance. Another example of this phenomenon is the case of Damaiyu harbor in Taizhou and Leqing harbor in Wenzhou, which are located on the eastern and western coasts of Leqing Bay, respectively, while sharing the same navigational channels and anchorage. In terms of natural (geophysical, geographical) attributes, they actually comprise one port, divided in two by an administrative boundary. The coexistence of Xiamen Port Authority, Zhangzhou Port Authority and Zhangzhou City Port Authority all located in close proximity in Xiamen Bay, results in particularly aggressive regional competition. Zhaoyin harbor controls $13 \mathrm{~km}$ of deep-water shoreline for the construction of $>33$ berths of $1 \times 10^{6} \mathrm{t}$ level and is thus in a position to compensate for the shortage associated with Xiamen port's deep-water shoreline. This resource complementarity has encouraged the ports in question to integrate their respective coastline resources. In these regions, shorelines distributed within the same bay are effectively partitioned by the administrative system into various individual harbors or ports; however, geophysical attributes inherently determine which provincial unit is in possession of these resources. Accordingly, the shoreline-associated physical attributes and the local administrative system are the chief determinants with regard to whether or not port integration takes place. More often than not, provincial government dominated port mergers are the most frequent integration mode within these geographical areas.

An important and inherently critical dynamic for effective port integration is the promotion of the rational and functional divisions between the ports and the achievement of complementary advantage through avoidance of disorderly competition. Within the Liaodong Peninsula, Dalian, Yingkou, Jinzhou and Dandong ports possess similar cargo structures which primarily comprise oil, grain, wood, metal ore, iron and steel, coal, non-metallic ores and fertilizers. Within this context, ports are requires to optimize their functionality via port integration, thus indicating that market-driven investments or strategic alliance have become the central 
mode of port integration across the administrative regions. Similarly, three harbors exist within Suzhou port, all of which possess distinctly different functions, namely, Taicang harbor (largest base of lubricating oil in China), and Changshu harbor (iron, steel and paper products) and Zhangjiagang harbor (wood). Accordingly, the prefecture-level governments have typically applied the port merger mode of integration to optimize port functionality within its jurisdictional scope. The underlying purpose of port integration within Tokyo Bay was the achievement of 'dislocation' development among the relevant ports. Tokyo port owns the advanced container terminals and undertakes shipping of industrial products and living necessities. Yokohama and Kawasaki ports primarily import industrial raw materials including crude oil, iron ore and grain, and subsequently export manufactured products from these materials. Chiba port primarily imports oil, gas, coal and iron ore while exporting automobiles, steel and ships.

\subsection{Port competition within same hinterland}

Since the mid-1990s, port construction and container handling capacity has increased dramatically in China, particularly in the context of port deregulation, which further stimulated the expansion of port capacity (Airriess, 2001). However, the increasing growth of export trade continued to decrease, China's port capacity confronted the surplus. According to the survey of Chinese Investment Consulting, port handling capacity in China exceeded actual demand by $>25 \%$. Upon further consideration of berths both planned and currently under construction, the nationwide handling capacity will realistically reflect a much higher surplus. As previously outlined, ports sharing the same hinterland generally result in aggressive competition, with the pursuit of local interests originating from typically localized port management further exacerbating this. Within this context, differing modes of port integration based primarily upon the market mechanism emerge, with investment in terminals across regions becoming increasingly frequent. These ports are typified by adjacent geographical location and share the same hinterland, resulting in recurrent construction and significantly disordered competition. This phenomenon is particularly commonplace in Bohai Rim and the YRD. Within the Liaodong Peninsula, Dalian Port has focused on the construction of berths for the containers, oil, groceries and bulk ore,
Yingkou Port has focused on refined oil products, liquid chemicals and iron ore, Jinzhou port typically concentrates on the transit of generic bulk cargo and container terminals while both Dandong and Huludao ports have traditionally focused on containers and petrochemicals. This significantly convergent structure necessitates the creation of intense competition within a geographical location. Another example of this is evidenced among the coastal ports in Shandong; imported iron ore for the iron and steel plants in Beijing, Jinan, Taiyuan, Shijiazhuang and Laiwu are delivered and unloaded in this locale, with the annual import volume maintained at approximately $1.4 \times 10^{7}-1.5 \times 10^{7}$ t. However, due to ever decreasing prices, port charges sunk to less than $60 \%$ of those proposed by the MOT, thus resulting in an annual loss of $1.1 \times 10^{10}$ yuan (RMB). Moreover, both port homogenization via significant construction and port competition exist within the YRD, thus reflecting critically conflicting approaches. Shanghai Municipality, Zhejiang and Jiangsu provinces have selected Yangshan, Ningbo and Suzhou, respectively, as their representative gateways for active participation within this highly competitive environment. An international shipping center is planned by Shanghai, with Jiangsu focusing on the construction of a large port located in Suzhou and Zhejiang preparing for the development of a one hundred-million- ton capacity port at Ningbo. These conflicting and oppositional construction projects, all located within the same hinterland, will likely result in the 'blind development' of scarce and valuable coastline resources, leading to 'blind expansion' of port infrastructure, thus further adding to an already increasing port capacity surplus. In this case, unreasonable distribution of collection and distribution systems may also result in a scarcity of long-distance hinterland, thus leading to insufficient cargo supply. As a consequence of these outlined factors, ports operating within the same hinterland are effectively forced to integrate in order to avoid aggressive competition; accordingly, port authorities in several coastal provinces have enacted programs which aim to optimize port resources (Cullinane et al., 2005). Terminal or harbor investments across regions by different terminal operators have increased in frequency. An exception to this has been the merging of ports via the establishment of a unified port authority, which has dominated port integration strategies in regions characterized by 'one bay-multi ports' (Hoshino, 2010). 
Effective regional development and the cultivation of regional growth pole require that the hub port and its adjacent small and medium-sized ports develop an explicitly functional division. Smaller ports adjacently located to a regional hub must seek collaboration with neighboring ports rather than enter into unnecessary and unhealthy competition, thereby increasing their chances of survival in an already competitive environment (Hoshino, 2010). Additionally, it is advisable that major hubs integrate with adjacent ports, such as Shanghai, Xiamen and Dalian. Within each region, hub or trunk ports typically implement these actively expanding strategies in order to enlarge their cargo supply and hinterland. Competition within the cluster of ports will primarily focus on the status of the hub port with the major task of port integration in this case being effective adjustment of the operational relationship between the hub port and neighboring trunk port. Moreover, terminal operators tend to invest in berth construction and related infrastructure at adjacent ports, based on the market mechanism to control terminal resources. For these reasons, Ningbo and Shanghai ports have undertaken regional integration within the YRD in order to better compete for the cargo coming from the YRV. Ningbo port, the major trunk port in the YRD, had owned the container berths in Suzhou, Taicang and Nanjing ports along the YR, in addition to building the terminal at Jiaxing port. The Zhejiang Government is currently expanding the ports of Zhoushan and Taizhou as potential feeder ports for Ningbo (Cullinane et al., 2005). On a more expansive scale, the new strategies implemented by Shanghai port are aimed at ensuring terminal access within long-distance hinterland and inland distribution systems (Rodrigue, 2003), with this integration further resulting in the emergence of a 'regionalization' phase within the YRV, primarily with respect to Shanghai port (Veenstra and Notteboom, 2011). Strategic alliances among ports across regions have becomes a dominant integration mode. Shanghai port, an internationally recognized major hub within the YRV, is adhering to a robust expansion strategy based around strategic investments along the YR in order to direct cargo flows to the deep-sea port (Veenstra and Notteboom, 2011). Accordingly, Shanghai port is implementing the 'Yangtze River Strategy' for the development of a logistics and distribution network via the expansion and management of terminal facilities; the strategy comprises the integra- tion of Chongqing, Wuhan, Jiujiang, Nanjing, Wuhu, Zhenjiang, Zhangjiagang and Nantong ports from the upper to lower reaches into its feeder shipping networks (Cullinane et al., 2005). The Shanghai Port Group, a categorically cross-regional organization, has been established in order to regulate competition and maintain current trajectory and velocity of port development in Shanghai, Zhejiang and Jiangsu provinces (Cullinane et al., 2005). While this process was initiated within the lower reaches, it is now moving upstream, with the outcomes ensuing from Shanghai's port integration proving instrumental for the objectified regionalization and associated feeder network (Lam and Yap, 2011; Veenstra and Notteboom, 2011).

\section{Discussion and Conclusions}

The Chinese port industry has experienced long-term annual traffic growth, thus reshaping and developing the organization positions of ports via integration strategies on a national basis. In concurrence with the deregulation of port control and rapid expansion of terminal infrastructure in China during the late 1990s, many seaports and a small number of river ports (excluding Guangdong Port) began port integration procedures, with an integration peak occurring during the period of 2005-2006. Port integration was found to develop within the context of two parallel drivers, namely, port mergers and recapitalization, with northern ports emphasizing the market mechanism and capital approach while the southern ports were characterized by their use of the governmental forces and mergers, thus reversing the current economic patterns within the two regions. Moreover, port integration in China was found to develop into 13 evolving pathways, the majority of which comprised regional hub ports as their core and final beneficiaries. The diversification of port integration has been shown to reflect these highlighted dynamics, particularly in the case of governmental and market mechanisms, as characterized by the emergence of a new unified port authority and the establishment of joint terminal ventures, respectively. During early periods of port integration in China, integration modes were typically government-driven, however, market forces now play an increasingly dominant role. In terms of spatial dimension, analyses indicate that the majority of cases in China reflect the differentiation between port internal 
integration, jurisdictional port integration, port integration across neighboring regions, regional port integration and hub-feeder port integration. Several causative factors underlying this differentiation have been highlighted. Significant factors include: the apparent enthusiasm shown by local governments pertaining to port construction following port deregulation during the late 1990s, disordered port expansion motivating these governments to strengthen port integration strategies. Furthermore, government-driven modes were shown to be most frequent during the early period of port integration while market-driven modes have dominated during more recent times. Both regional and port planning have become significant guidance instruments, with both also actively promoting the diversification of port integration strategies; while regional planning tends to emphasize diversified integration across administrative boundaries, port planning is directed towards port mergers. Coastline resource harmonization, particularly in regions described as 'one bay-multi ports', has become a critical facet of port integration, while the aforementioned port mergers are becoming ever more frequently employed. Growing demands have been placed on the port integration process over recent years due to the so called 'blind development' of sparse coastlines, in addition to increased demands on port handling capacity due to local and regional competition; accordingly, intra-regional investment by terminal operators is becoming a more frequently encountered phenomenon. Moreover, hub ports are now actively integrating adjacent feeder ports in order to establish feeder shipping networks, thus investments are being made based on both the market mechanism and intra-regional strategic alliances.

While port integration in China continues to exhibit significant growth, operational difficulties exist and have been highlighted in the current research. Firstly, the majority of case data included in the current review represent a statistical summary of the ports' throughput and terminal facility; accordingly, the full integration of port functionality and integration effects are not possible to quantify, i.e., available data denote a 'physical summation' as opposed to the 'chemical reaction'. Moreover, integrated ports are in many cases still highly operationally dependent, and retained their harbors and boat governance, maritime authorities and customs, commodity inspection bureau, fronted defense inspection bureau and MSA Bureau, thus resulting in a failure to fully unify. Secondly, ports have traditionally represented a lifeline for local and regional development and are therefore characterized by primarily local interests. Upon integration, port managers and/or authorities frequently continue to operate in competition with their 'partner' port for resources including core status, operational area and investment, thus effectively negating integration principals and failing to optimize shared resources. Finally, many coastal regions continue to construct new ports or enlarge existing ports, even in the face of failing to effectively achieve current design capacity, further exacerbating disordered expansion and development during various phases of port integration.

Within this context, the underlying principal of port integration primarily seeks to maintain and increase the current trajectory of port growth via the expansion of hinterland and market; however, participants and shareholders are required to rethink these strategies and refocus on the optimization of interior port resources as opposed to exterior resources, over which they may exert little or no control. It is concluded that the port integration trajectory will continue to increase, with market-driven modes likely dominating the process. More specifically, terminal operators controlled by the larger hub ports will invest in the construction and operation of terminals and harbors at medium and small-scale ports, such as the Shanghai Port and the ports in the YRV, Guangzhou port and the ports in the PRV, and Ningbo Port and its adjacent ports. These analyses and subsequent findings may be used to inform and thus increase current understanding of the developing characteristics of seaports and inland river ports in China. More significantly, this work may be utilized to enhance and enrich current operational relationships between the ports and the dynamics mechanisms associated with port geography, thus addressing the significant paucity previously existing within the current literature.

\section{References}

Airriess C A, 2001. The regionalization of Hutchison Port Holdings in Mainland China. Journal of Transport Geography, 9(4): 267-278. doi: 10.1016/S0966-6923(01)00020-5

Cao Youhui, Mao Hanying, Xu Gang, 2001. The functional structure of the lower Changjiang River Port System. Scientia Geographical Sinica, 56(5): 590-598. (in Chinese)

Chen Hang, Luan Weixin, Wang Yuewei, 2005. Coordinate development of seaport cluster around Bohai Sea. Ocean Development and Management, (2): 66-71. (in Chinese) 
China Transportation \& Communications Press, 2014. The Year Book of Chinese Transportation (2013). Beijing: China Transportation \& Communications Press.

Comtois C, Slack B, 2000. Terminaux de transport et grande re'gion urbaine: L'inte'gration de Hong Kong dansles performances de la Chine. Perspectives Chinoises, 58(2): 12-20. doi: 10.3406/perch.2000.2479

Cullinane K, Teng Y H, Wang T F, 2005. Port competition between Shanghai and Ningbo. Maritime Policy \& Management, 32(4): 331-346.

Ducruet C, van der Horst M, 2009. Transport integration at European ports: measuring the role and position of intermediaries. European Journal of Transport and Infrastructure Research, 9(2): 121-142.

Givoni M, Banister D, 2006. Airline and railway integration. Transport Policy, 13(5): 386-397. doi: 10.1016/j.tra.2013.01. 014

Han Zenglin, An Xiaopeng, Wang Li et al., 2002. Distribution and optimization of container transport network in China. Scientica Geographical Sinica, 57(4): 479-488. (in Chinese)

Heaver T D, 1995. The implications of increased competition among ports for port policy and management. Maritime Policy and Management, 22(2): 125-133. doi: 10.1080/0308883950 0000045

Hoshino H, 2010. Competition and collaboration among container ports. The Asian Journal of Shipping and Logistics, 26(1): 31-48. doi: 10.1016/S2092-5212(10)80010-0

Junior G A D S, Beresford A K C, Pettit S J, 2003. Liner shipping companies and terminal operators: internationalization or globalization? Maritime Economics \& Logistics, 5(4): 393 412. doi: 10.1057/Palgrave.mel.9100088

Lam J S L, Yap W Y, 2011. Dynamics of liner shipping network and port connectivity in supply chain systems: analysis on East Asia. Journal of Transport Geography, 16(6): 1272-1281. doi: 10.1016/j.jtrangeo.2011.06.007

Lee S Y, Rodrigue J P, 2006. Trade reorientation and its effects on regional port systems: the Korea-China link along the Yellow Sea Rim. Growth and Change, 37(4): 597-619. doi: 10.1111/j.1468-2257.2006.00342.X

Li J B, Oh Y S, 2010. A research on competition and cooperation between Shanghai port and Ningbo-Zhoushan port. The Asian Journal of Shipping and Logistics, 26(1): 67-92. doi: 10.1016/S2092-5212(10)80012-4

Notteboom T E, 2002. Consolidation and contestability in the European container handling industry. Maritime Policy \& Management, 29(3): 257-269. doi: 10.1080/0308883021013 2614

Notteboom T E, Rodrigue J P, 2008. Containerisation, box logistics and global supply chains: the integration of ports and liner shipping networks. Maritime Economics \& Logistics, 10(1): 152-174. doi: 10.1057/Palgrave.mel.9100196

Notteboom T E, Rodrigue J P, 2012. The corporate geography of global container terminal operators. Maritime Policy and Management, 39(3): 249-279. doi: 10.1080/03088839.2012. 671970

Notteboom T E, Winkelmans W, 2001. Structural changes in logistics: How will port authorities face the challenge? Maritime Policy and Management, 28(1): 71-89. doi: 10.1080/ 03088830119197

Pallis A A, Notteboom T E, De Langen P W, 2008. Concession agreements and market entry in the container terminal industry. Maritime Economics \& Logistics, 10(3): 209-228. doi: $10.1057 / \mathrm{mel} .2008 .1$

Rodrigue J P, 2003. The port authority of New York and New Jersey: Global changes, regional gains and local challenges in port development. Les Cahiers Scientifiques $d u$ Transport, (44): 55-75. doi: 10.1111/j.0033-0124.1988.00288.x

Slack B, Fr'emont A, 2005. Transformation of port terminal operations: from the local to the global. Transport Reviews, 25(1): 117-130. doi: 10.1080/0144164042000206051

Slack B, Wang J J, 2002. The challenge of peripheral ports: an Asian perspective. GeoJournal, 56(2): 159-166. doi: 10.1016/ S0966-6923(02)00003-0

Song D W, 2002. Regional port competition and co-operation: The case of Hong Kong and South China. Journal of Transport Geography, 10(2): 99-110. doi: 10.1016/S0966-6923(02) 00003-0

Song D W, Panayides P M, 2008. Global supply chain and port/terminal: Integration and competitiveness. Maritime Policy \& Management, 35(1): 73-87. doi: 10.1080/03088830701 848953

Stubbs J, Jegede F, 1998. The integration of rail and air transport in Britain. Journal of Transport Geography, 6(1): 53-67. doi: 10.1016/S0966-6923(97)00039-2

Veenstra A, Notteboom T E, 2011. The development of the Yangtze River container port system. Journal of Transport Geography, 19(4): 772-781. doi: 10.1016/j.jtrangeo.2010. 09.006

Wang Chengjin, Ducruet C, 2012. New port development and global city making: emergence of the Shanghai-Yangshan multilayered gateway hub. Journal of Transport Geography, 25(6): 58-69. doi: 10.1016/j.jtrangeo.2012.07.008

Wang J J, 1998. A container load center with a developing hinterland: a case study of Hong Kong. Journal of Transport Geography, 6(3): 187-201. doi: 10.1016/S0966-6923(98)000118

Wang J J, Michael CC, 2010. From a hub port city to a global supply chain management center: a case study of Hong Kong. Journal of Transport Geography, (18): 104-115. doi: 10. 1016/j.jtrangeo.2009.02.009

Wang J J, Ng A K Y, Olivier D, 2004. Port governance in China: a review of policies in an era of internationalizing port management practices. Transport Policy, 11(3): 237-250. doi: 10.1016/j.tranpol.2003.11.003

Wang J J, Olivier D, Notteboom T E et al., 2007. Ports, Cities, and Global Supply Chains. Ashgate, Aldershot.

Wang J J, Slack B, 2000. The evolution of a regional container port system: the Pearl River Delta. Journal of Transport Geography, 8(4): 263-275. doi: 10.1016/S0966-6923(00)00013-2

Wang Renxiang, 2008. Strategy of port resource integration in China-case of Ningbo-Zhoushan. Economic Geography, 28(5): 872-875. (in Chinese) 